\title{
Effect of land model ensemble versus coupled model ensemble on the simulation of precipitation climatology and variability
}

\author{
Jiangfeng Wei ${ }^{1,2}(\mathbb{D}) \cdot$ Paul A. Dirmeyer ${ }^{3} \cdot{\text { Zong-Liang } \text { Yang }^{2} \cdot \text { Haishan Chen }}^{1}$
}

Received: 15 August 2017 / Accepted: 20 October 2017 / Published online: 31 October 2017

(C) The Author(s) 2017. This article is an open access publication

\begin{abstract}
Through a series of model simulations with an atmospheric general circulation model coupled to three different land surface models, this study investigates the impacts of land model ensembles and coupled model ensemble on precipitation simulation. It is found that coupling an ensemble of land models to an atmospheric model has a very minor impact on the improvement of precipitation climatology and variability, but a simple ensemble average of the precipitation from three individually coupled land-atmosphere models produces better results, especially for precipitation variability. The generally weak impact of land processes on precipitation should be the main reason that the land model ensembles do not improve precipitation simulation. However, if there are big biases in the land surface model or land surface data set, correcting them could improve the simulated climate, especially for well-constrained regional climate simulations.
\end{abstract}

Electronic supplementary material The online version of this article (https://doi.org/10.1007/s00704-017-2310-7) contains supplementary material, which is available to authorized users.

Jiangfeng Wei

jwei@nuist.edu.cn

1 Collaborative Innovation Center on Forecast and Evaluation of Meteorological Disasters/Key Laboratory of Meteorological Disaster, Ministry of Education/International Joint Research Laboratory on Climate and Environment Change, Nanjing University of Information Science and Technology, Nanjing 210044, China

2 Jackson School of Geosciences, University of Texas at Austin, Austin, TX 78712, USA

3 Center for Ocean-Land-Atmosphere Studies, George Mason University, Fairfax, VA 22030, USA

\section{Introduction}

Land surface processes include complex interactions of various hydrological, biogeophysical, and biogeochemical processes, and it is a challenge to describe them with numerical models. Land surface models (LSMs) have evolved from the first-generation buck-type schemes in the 1960s, the secondgeneration schemes with biophysics in the 1980s, to the thirdgeneration schemes with carbon cycle and dynamic vegetation (Sellers et al. 1997; Pitman 2003). However, due to the complexity of the land surface processes and the scarcity of large-scale land surface observations, current LSMs still have large uncertainties in simulating the surface processes (e.g., Dirmeyer et al. 2006a; Dirmeyer et al. 2006b; Jimenez et al. 2011). When driven by the same atmospheric forcing, different LSMs may give significantly different surface fluxes (Henderson-Sellers et al. 1995; Henderson-Sellers et al. 1996; Pitman et al. 1999).

As land surface is an important component of the climate system, the discrepancies among LSMs can impact the simulations with the coupled climate models through surface fluxes. Wei et al. (2010a) coupled one atmospheric general circulation model (AGCM) with three different LSMs and investigated the impact of different LSMs and land-atmosphere coupling on climate simulation. It was found that for surface variables, like latent and sensible heat fluxes and surface air temperature, atmospheric feedback may amplify or reduce the discrepancies caused by different LSMs, depending on the different local climate and feedback processes. Further studies showed that in the land-atmosphere coupled model simulations, the precipitation variability, predictability, and land-atmosphere coupling strength are mainly determined by the AGCM, rather than the LSM (Wei and Dirmeyer 2010; Wei et al. 2010b). 
Due to limitations in understanding and representing various physical processes in models, every model has biases. The multi-model ensemble (MME) is a common method to counteract the biases from different models and to get better simulation and prediction results (e.g., Reichler and Kim 2008). This approach is based on the fact that the biases of the models are more or less independent. In addition, due to the chaotic nature of atmospheric and oceanic evolutions, the model simulations are also sensitive to initial conditions. Perturbing initial conditions is a way to consider the effect of their uncertainties (e.g., Stensrud et al. 2000; Zhu et al. 2012; Zhu et al. 2013). In this study, we mainly consider the effect of model biases and how MME may improve the simulations. MME has been applied to both coupled earth system models (Krishnamurti et al. 2000; Barnston et al. 2003; Palmer et al. 2004; Kirtman et al. 2014) and offline LSMs (Guo et al. 2007), and it was found that results from MME are generally better than those from most individual models. An unexplored problem is whether a land model ensemble can improve climate simulations in coupled land-atmosphere models and how effective the land model ensemble is compared to the traditional MME across the coupled models. Land strongly responds to the forcings from atmosphere, but is less chaotic as the dynamical fluid systems like atmosphere and ocean. In this study, we expand the work of Wei et al. (2010a) with additional experiments and analyses, with a focus on the impacts of model ensembles on the simulated climatology and variability of precipitation.

\section{Model and experiments}

One AGCM and three LSMs are used for the experiments (same as in Wei et al. (2010a)). The AGCM used is version 3.2 of the Center for Ocean-Land-Atmosphere Studies (COLA) AGCM (Misra et al. 2007). It has 28 vertical sigma levels, and the horizontal is at T62 spectral resolution $\left(\sim 1.9^{\circ} \times 1.9^{\circ}\right)$. Three LSMs are coupled to the AGCM in this study: the simplified simple biosphere model (SSiB) (based on Xue et al. (1991); Dirmeyer and Zeng (1999)), the Community Land Model (CLM) version 3.5 (Oleson et al. 2008), and version 2.7 of the Noah land model (Ek et al. 2003). These LSMs have been widely used in weather and climate research. They have different numbers of soil layers
Fig. 1 The three types of experiments. a Individually coupled. b Combined. c Selected

\section{(a) Individually coupled experiment}
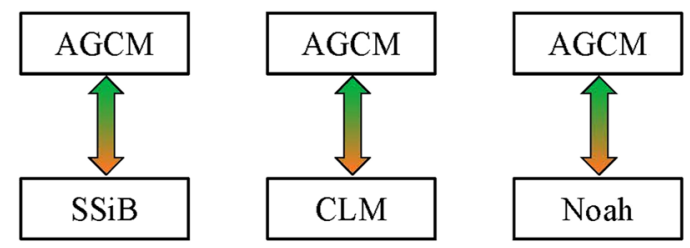

(b) Combined experiment

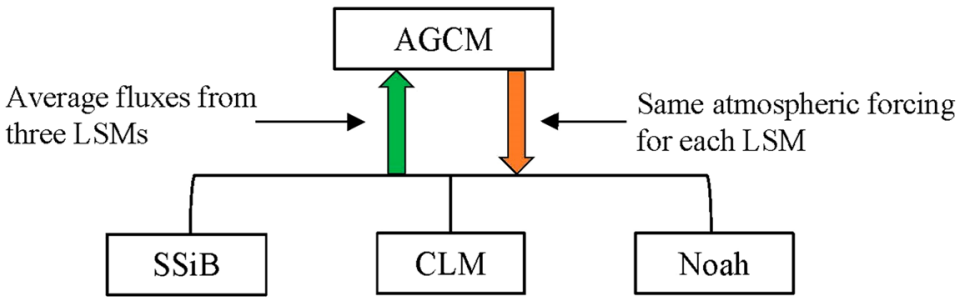

\section{(c) Selected experiment}

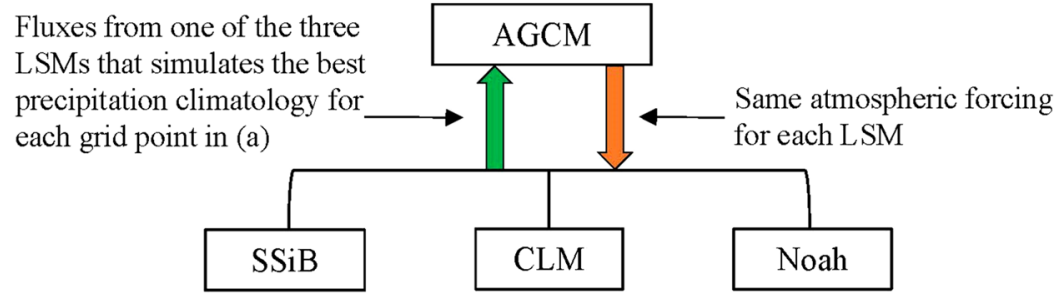


and soil depths, and each uses its own soil and vegetation data sets. There are many differences among these LSMs in the parameterization of specific processes - please refer to the references above for more details. The coupling between LSMs and the AGCM and model simulations is all conducted at $\mathrm{T} 62$ resolution. The integration time step is the same for the LSMs and the AGCM (12 min). There has been no tuning or nudging in the coupling for all the model combinations.

Three sets of experiments are performed for this study, and they are shown schematically in Fig. 1. In the first experiment, the three LSMs are coupled to the AGCM individually (Fig. 1a). In the second experiment, called "combined," an innovative coupling method is used to couple the three LSMs to the AGCM in combination with a shared atmosphere. Over each grid point and at every time step, the LSMs receive the same atmospheric forcing from the AGCM, calculate their state variables and surface fluxes separately, and the average surface fluxes from the three LSMs are passed back to the AGCM (Fig. 1b). In the third experiment, called "selected," we first compared the simulated monthly precipitation climatology from the individually coupled runs in the first experiment with the observation-based Global Precipitation Climatology Project (GPCP) v3.2 precipitation (2.5 grid interpolated to the model grid; Adler et al. (2003)), and in each of the 12 months and over each grid point we select one of the three runs that the simulated mean precipitation is closest to that of GPCP (Fig. 2). The new simulation is similar to that in the second experiment, but in each month and over each grid point, only the surface fluxes from one selected LSM are passed back to the AGCM (Fig. 1c).

Actually, the same code is run for all three experiments; the difference is effectively in the weights applied to the fluxes calculated by each LSM. Running with any single LSM is equivalent to assigning the fluxes (including sensible, latent, momentum, surface reflected shortwave, and upward longwave fluxes) from that scheme a weight of 1.0 and 0.0 for the other two. In the second experiment (combined run), each LSM receives identical 1/3 weight, so each LSM has equal opportunity to impact the atmosphere. In the third experiment (selected run), a weight of 1.0 is given to one of the LSMs, which varies monthly and over points. The purpose of the second experiment is to investigate whether the land model ensemble results in a better precipitation simulation, and the purpose of the third experiments is to examine whether using the "best" land model at each grid point can produce an overall better simulation for the globe.

All the simulations start from April 1, 1982 and end on January 1, 2005 (nearly 23 years) and are forced by the weekly sea surface temperature from observations (Reynolds et al. 2002). After spin-up, the last 18 years of data are used for analysis. In addition to the three experiments, we also calculate the monthly ensemble mean precipitation of the three individually coupled simulations; it is called " 3 -model
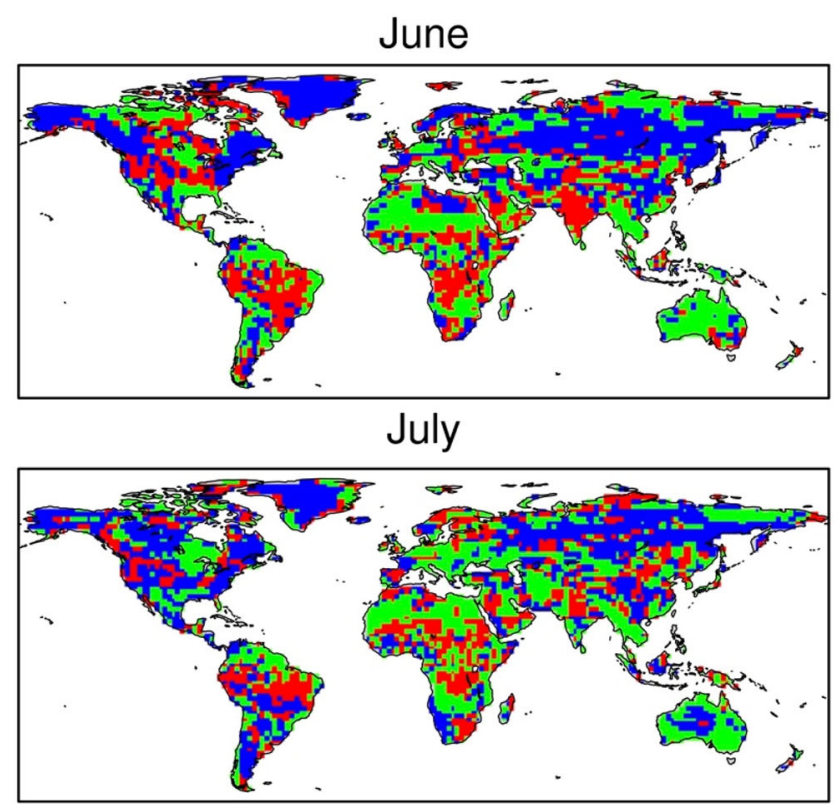

August

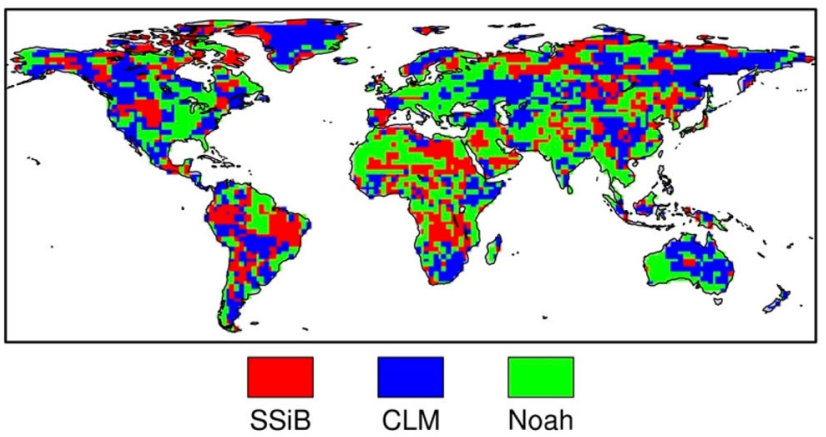

Fig. 2 Models that are selected for coupling over each grid point for the selected run. Each of the 12 months has a different pattern, but only June, July, and August are shown here

average" in the analysis. As observationally based precipitation data still have substantial uncertainties (e.g., Fekete et al. 2004), we used both GPCP data (based on both gauge observations and satellite estimates) at $2.5^{\circ}$ resolution and the Climate Prediction Center (CPC) Unified Gauge-Based Analysis of precipitation (Xie et al. 2007; Chen et al. 2008) at $0.5^{\circ}$ resolution for model evaluation. The results based on two precipitation data sets are similar and we only show evaluations based on GPCP data in the paper, and please check the supplementary material for evaluations based on CPC data.

\section{Results}

We first compare the simulated precipitation climatology from different experiments with the observations from GPCP (Fig. 3). The climatologies of the different simulations show similar spatial correlations with GPCP. The global mean precipitation from GPCP is in the range of the three individually 
Fig. 3 The annual mean land precipitation of 1987-2004 a from the observational data of GPCP and $\mathbf{b}-\mathbf{g}$ the spatial patterns of experiments minus GPCP. Unit: $\mathrm{mm} /$ day. The first number in the corner of each panel is the global average of the mean precipitation (not difference), and the second number in the parentheses is the spatial correlation (uncentered) of the mean precipitation between model experiments and GPCP

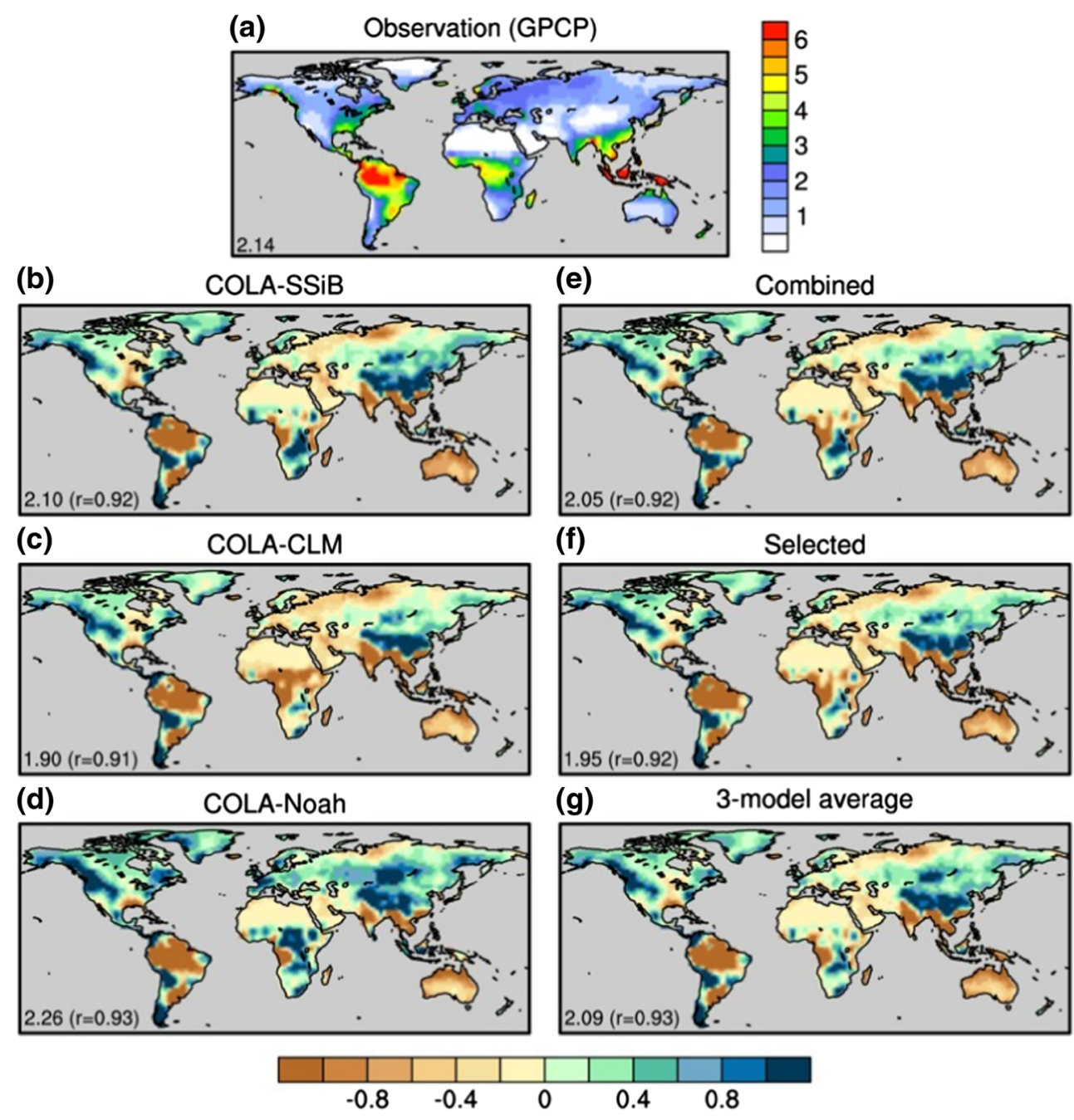

coupled simulations, and the combined and selected simulations are also in this range. Except over parts of Africa, the different model simulations show similar spatial patterns in biases, which indicates that most biases in these experiments are probably not related to the LSMs, although there is a chance that all of the three LSMs are biased in the same way. The divergence of biases over Africa could be a sign that the land processes here are more important than those in other regions, consistent with the study of Wei et al. (2016).

Next, we focus on examining whether the combined and selected ensemble experiments and the 3-model average (hereafter we call all of them ensemble experiments) produce more accurate precipitation than the individually coupled simulations. Figure 4 shows the total number of individually coupled runs that produces a less accurate precipitation climatology than the ensemble experiments. A number of 3 denotes that the results of the ensemble experiments are more accurate than all of the three individually coupled runs.

Note that there are only four possible values in Fig. $4(0,1$, 2 , and 3 ), and for a random uniform distribution each value will be for $25 \%$ of the grid points. If the percentage of grid points with a value (two values) is not much larger than $25 \%$ (50\%), the impact associated with the value (two values) is not globally significant.

It can be seen in Fig. 4 that the percentage of grid points with a value of 3 , i.e., the ensemble is more accurate than all of the individually coupled runs, is much less than $25 \%$, and for values of both 2 and 3, i.e., the ensemble experiment is more accurate than at least two individually coupled runs, only the 3-model average has more than $50 \%$ points (64\% for JJA and $58 \%$ for DJF). This suggests that the combined and selected experiments do not produce a significantly better precipitation climatology than the individually coupled runs, and a simple MME may produce better precipitation climatology than the individually coupled simulations and the ensemble simulations based on multiple LSMs. The selected run, although using an LSM that can simulate the best precipitation climatology at each grid point, does not show an overall better precipitation climatology 
JJA

(a)

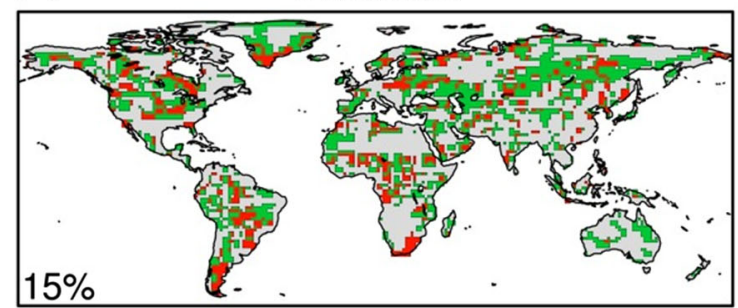

(c)

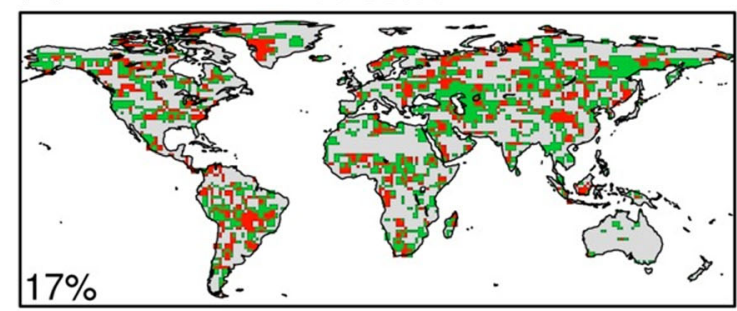

(e) 3-model average

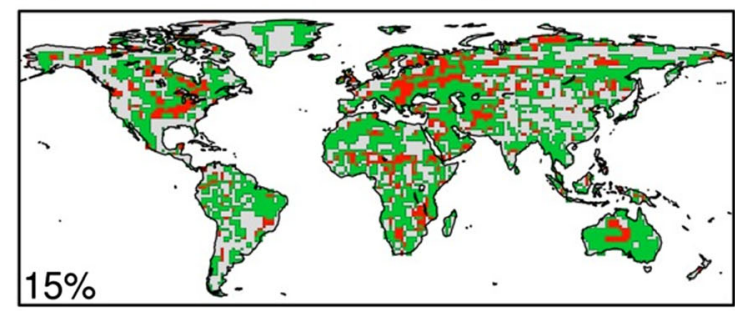

2

Fig. 4 The number of the individually coupled runs that are inferior (relative to GPCP) to a, b combined; c, $\mathbf{d}$ selected; and $\mathbf{e}, \mathbf{f} 3$-model average in the simulated annual average precipitation. JJA (left) and

compared to the individually coupled runs or the combined run.

Figure 5 shows the areas where the ensemble is more accurate than the individual runs in variance. It is evident that the 3-model average performs much better than the combined and selected runs, and the selected run performs slightly better than the combined run. The advantage of the 3 -model average is even more evident in the simulated monthly variability of the precipitation time series evaluated with the Pearson correlation coefficient (Fig. 6). The monthly correlation with GPCP from the 3-model average is higher than all (at least two) of the individually coupled runs over $61 \%$ (90\%) of the grid points. Note that the 3-model ensemble average can reduce the random noise/error of individual members, which leads to lower variance. However, this part of variance is much smaller than the month-tomonth variance caused by seasonal cycle or other external forcings when seasonal cycle is removed (e.g., ENSO), so the impact of ensemble average on the
DJF

(b) Combined

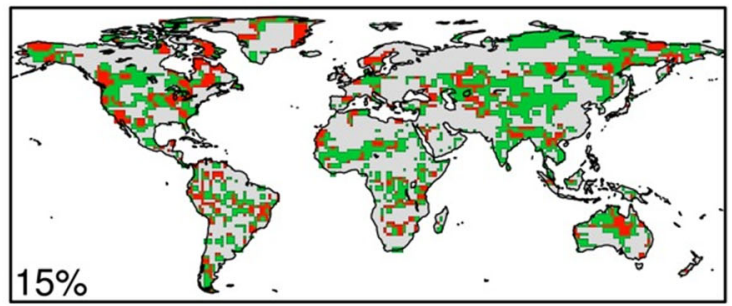

(d) Selected

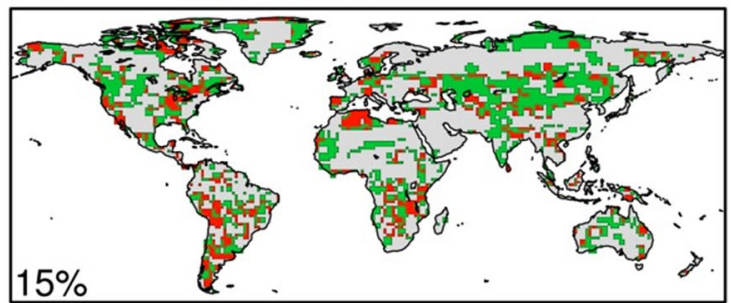

(f) 3-model average

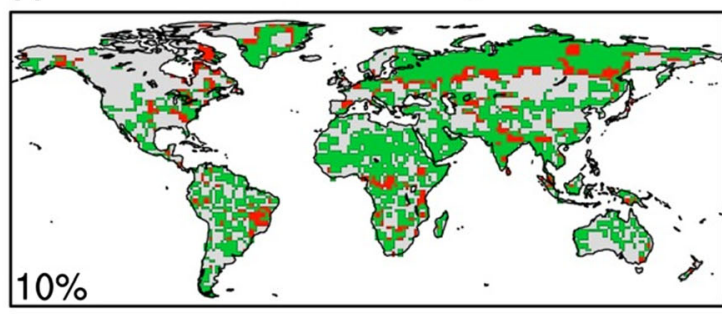

3

DJF (right) of 1987-2004. Only the numbers greater than 1 are shown, and the percentages of land grid points that are in red are shown in each panel

evaluation of monthly precipitation variability should be weak.

\section{Discussion and concluding remarks}

This study compares the impact of land model ensembles and coupled model ensemble on precipitation simulation. It is found that the land ensemble, including both combined and selected, have a very minor impact on the simulated precipitation climatology and variability, but a simple ensemble average of the precipitation from three individually coupled models produces better results, especially for precipitation variability.

The limited impact of local land processes on precipitation has been reported in some previous studies (e.g., Gao et al. 2008; Koster et al. 2011; Wei et al. 2016). Even if a land model ensemble can produce better land surface state and fluxes (Guo et al. 2007), their impacts on precipitation are often overshadowed by atmospheric 


\section{Original time series}

(a)

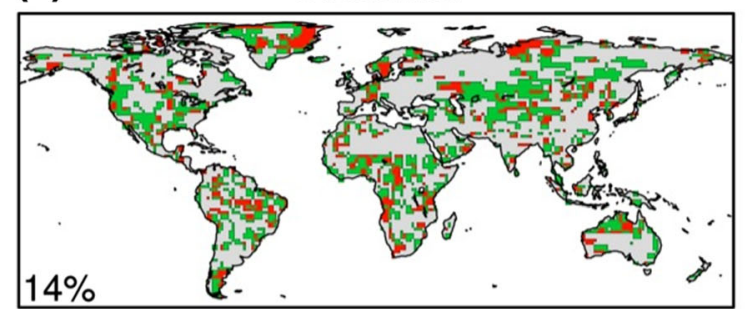

(c)

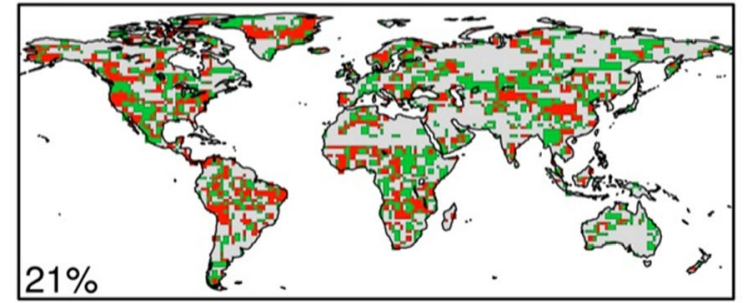

(e) 3-model average
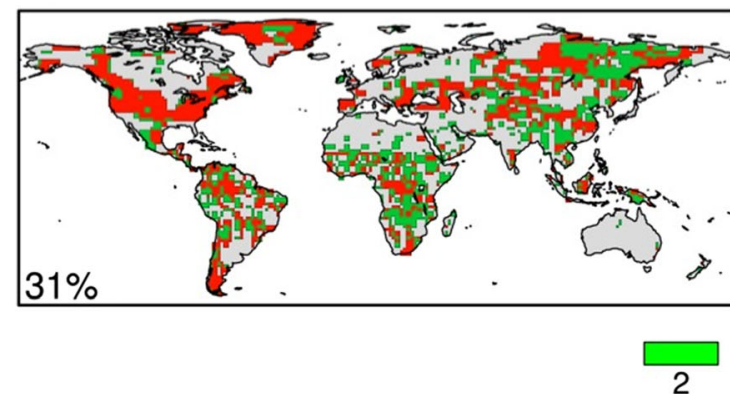

Seasonal cycle removed

(b) Combined

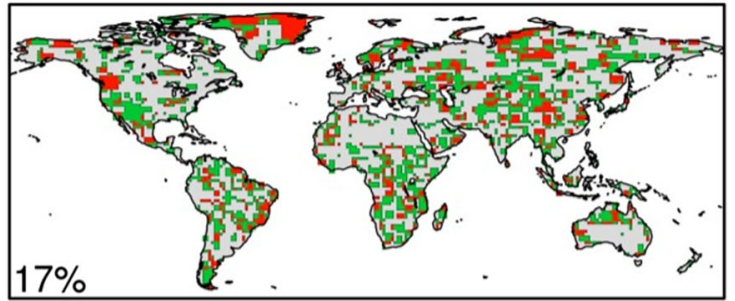

(d)

Selected

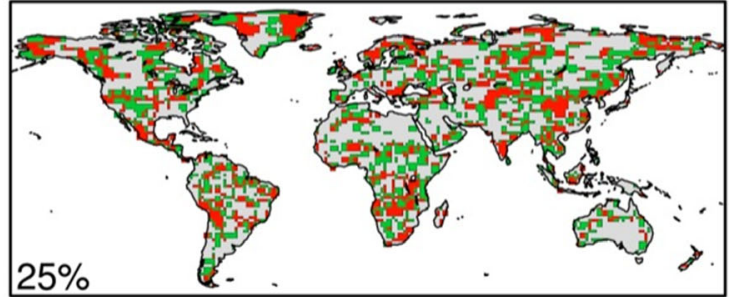

(f)

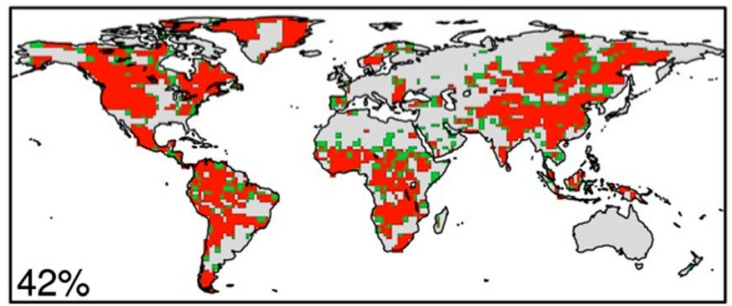

3

Fig. 5 Same as Fig. 4, but for the variance of month to month precipitation during 1987-2004. Original precipitation time series (left); seasonal cycles in the time series are removed (right)

processes, making the precipitation response weak and difficult to detect. By well-controlled model experiments and sophisticated statistical analysis, some hotspots of the impact of soil moisture on precipitation have been identified according to a designed coupling strength (Koster et al. 2004). However, as this coupling strength mathematically corresponds to the percentage of precipitation variance caused by prescribed soil moisture in the models (Koster et al. 2006; Yamada et al. 2007), it can be found that even in those hotspot regions the contributions of soil moisture to precipitation variability are still low (mostly $<10 \%)$. Similar coupling strengths are also found for the models used in this study (Wei et al. 2010b). The generally weak impact of land processes on precipitation should be the main reason that land model ensembles do not improve precipitation simulation. Another possible contributing factor is that land processes are less chaotic than the dynamic atmospheric processes and the variabilities of land surface fluxes are largely determined by the atmospheric forcing. With the same atmospheric forcing, less independent model biases can be reduced by an ensemble average of LSMs.

This research suggests that if the model representation of atmospheric processes has strong biases, improvements in the LSM can rarely improve these biases. However, if the atmospheric processes are properly represented while the land surface processes have strong biases, a better LSM or more accurate land surface data set may help improve climate simulations in coupled models (e.g., Hagemann et al. 2016; Lin et al. 2016), especially in regional climate simulations where the atmosphere is constrained by boundary forcing so the signals from land surface stand out (e.g., Steiner et al. 2009; Lorenz et al. 2012).

We only show the simulation results of precipitation, but our preliminary analyses show that surface variables like ET and surface temperature have similar results. This may be because precipitation and the associated cloud cover have a strong impact on the surface water and energy balances, so their variabilities are similar. Although the ensemble size in this study is only three, the results are reasonable and consistent with our previous knowledge. The results from this 
(a)

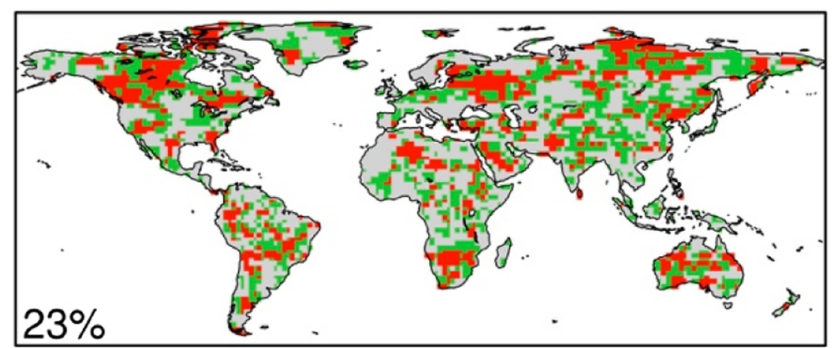

(b)

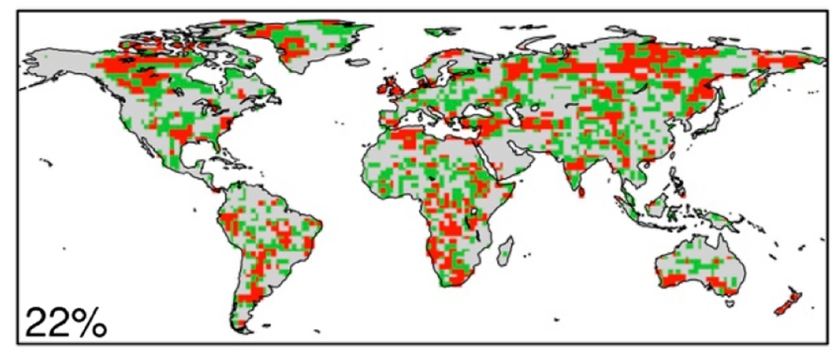

(c)

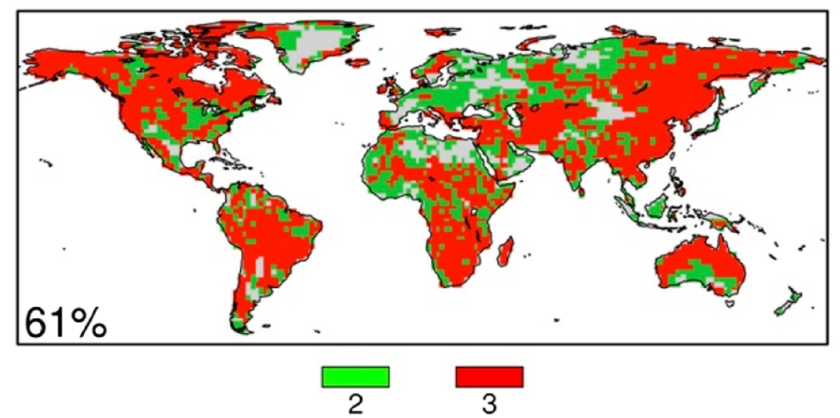

Fig. 6 Same as Fig. 4, but for the correlation of month to month precipitation with observations from GPCP during 1987-2004

study can provide guidance for the future design of model ensembles for climate simulation and prediction.

Acknowledgements This work was supported by a start-up grant to the first author from the Nanjing University of Information Science and Technology.

Open Access This article is distributed under the terms of the Creative Commons Attribution 4.0 International License (http:// creativecommons.org/licenses/by/4.0/), which permits unrestricted use, distribution, and reproduction in any medium, provided you give appropriate credit to the original author(s) and the source, provide a link to the Creative Commons license, and indicate if changes were made.

\section{References}

Adler RF et al (2003) The version-2 global precipitation climatology project (GPCP) monthly precipitation analysis (1979-present). J Hydrometeor 4:1147-1167. https://doi.org/10.1175/15257541(2003)004<1147:Tvgpcp>2.0.Co;2

Barnston AG, Mason SJ, Goddard L, Dewitt DG, Zebiak SE (2003) Multimodel ensembling in seasonal climate forecasting at IRI.
Bull Am Meteorol Soc 84:1783-1796. https://doi.org/10.1175/ BAMS-84-12-1783

Chen MY, Shi W, Xie PP, Silva VBS, Kousky VE, Higgins RW, Janowiak JE (2008) Assessing objective techniques for gauge-based analyses of global daily precipitation. J Geophys Res 113. doi:https://doi.org/ 10.1029/2007jd009132

Dirmeyer PA, Zeng FJ (1999) An update to the distribution and treatment of vegetation and soil properties in SSiB. COLA Tech Rep 78, 25 pp

Dirmeyer PA, Gao XA, Zhao M, Guo ZC, Oki TK, Hanasaki N (2006a) GSWP-2 - multimodel analysis and implications for our perception of the land surface. Bull Am Meteorol Soc 87:1381-1397. https:// doi.org/10.1175/Bams-87-10-1381

Dirmeyer PA, Koster RD, Guo Z (2006b) Do global models properly represent the feedback between land and atmosphere? J Hydrometeorol 7:1177-1198. https://doi.org/10.1175/JHM532.1

Ek MB, et al (2003) Implementation of Noah land surface model advances in the National Centers for Environmental Prediction operational mesoscale Eta model. J Geophys Res 108. doi:https://doi.org/ 10.1029/2002JD003296

Fekete BM, Vörösmarty CJ, Roads JO, Willmott CJ (2004) Uncertainties in precipitation and their impacts on runoff estimates. J Clim 17: 294-304. https://doi.org/10.1175/1520-0442(2004)017<0294: UIPATI $>2.0 . \mathrm{CO} ; 2$

Gao X, Dirmeyer PA, Guo ZC, Zhao M (2008) Sensitivity of land surface simulations to the treatment of vegetation properties and the implications for seasonal climate prediction. J Hydrometeorol 9:348-366. https://doi.org/10.1175/2007jhm931.1

Guo Z, Dirmeyer PA, Gao X, Zhao M (2007) Improving the quality of simulated soil moisture with a multi-model ensemble approach. Q J R Meteorol Soc 133:731-747. https://doi.org/10.1002/qj.48

Hagemann S, Blome T, Ekici A, Beer C (2016) Soil-frost-enabled soilmoisture-precipitation feedback over northern high latitudes. Earth Syst Dynam 7:611-625. https://doi.org/10.5194/esd-7-611-2016

Henderson-Sellers A, Pitman AJ, Love PK, Irannejad P, Chen TH (1995) The project for intercomparison of land-surface parameterization schemes (PILPS) - phase-2 and phase-3. Bull Am Meteorol Soc 76:489-503. https://doi.org/10.1175/1520-0477(1995)076<0489: Tpfiol $>2.0 . \mathrm{Co} ; 2$

Henderson-Sellers A, McGuffie K, Pitman AJ (1996) The project for intercomparison of land-surface parametrization schemes (PILPS): 1992 to 1995. Clim Dyn 12:849-859. https://doi.org/10.1007/ s003820050147

Jimenez C et al (2011) Global intercomparison of 12 land surface heat flux estimates. J Geophys Res 116. doi: https://doi.org/10.1029/ 2010jd014545

Kirtman BP et al (2014) The North American multimodel ensemble phase-1 seasonal-to-interannual prediction; phase-2 toward developing intraseasonal prediction. Bull Am Meteorol Soc 95:585-601. https://doi.org/10.1175/Bams-D-12-00050.1

Koster RD et al (2004) Regions of strong coupling between soil moisture and precipitation. Science 305:1138-1140. https://doi.org/10.1126/ science. 1100217

Koster RD et al (2006) GLACE: the global land-atmosphere coupling experiment. Part I: overview. J Hydrometeor 7:590-610. https:// doi.org/10.1175/Jhm510.1

Koster RD et al (2011) The second phase of the global land-atmosphere coupling experiment: soil moisture contributions to subseasonal forecast skill. J Hydrometeorol 12:805-822. https://doi.org/10. 1175/2011JHM1365.1

Krishnamurti TN et al (2000) Multimodel ensemble forecasts for weather and seasonal climate. J Clim 13:4196-4216. https://doi.org/10.1175/ 1520-0442(2000)013<4196:MEFFWA >2.0.CO;2

Lin PR, Wei JF, Yang ZL, Zhang YF, Zhang K (2016) Snow data assimilation-constrained land initialization improves seasonal temperature prediction. Geophys Res Lett 43:11423-11432. https://doi. org/10.1002/2016g1070966 
Lorenz R, Davin EL, Seneviratne SI, 2012 Modeling land-climate coupling in Europe: impact of land surface representation on climate variability and extremes. J Geophys Res 117. doi: https://doi.org/10. 1029/2012jd017755

Misra V et al (2007) Validating and understanding the ENSO simulation in two coupled climate models. Tellus Ser A Dyn Meteorol Oceanogr 59:292-308. https://doi.org/10.1111/j.1600-0870.2007. 00231.x

Oleson KW et al (2008) Improvements to the community land model and their impact on the hydrological cycle. J Geophys Res Biogeosci 113. doi: https://doi.org/10.1029/2007jg000563

Palmer TN et al (2004) Development of a European multimodel ensemble system for seasonal-to-interannual prediction (DEMETER). Bull Am Meteorol Soc 85:853-872. https://doi.org/10.1175/BAMS-856-853

Pitman AJ (2003) The evolution of, and revolution in, land surface schemes designed for climate models. Int J Climatol 23:479-510. https://doi.org/10.1002/joc.893

Pitman AJ et al (1999) Key results and implications from phase 1(c) of the project for intercomparison of land-surface parametrization schemes. Clim Dyn 15:673-684. https://doi.org/10.1007/ s003820050309

Reichler T, Kim J (2008) How well do coupled models simulate today's climate? Bull Am Meteorol Soc 89:303-311. https://doi.org/10. 1175/BAMS-89-3-303

Reynolds RW, Rayner NA, Smith TM, Stokes DC, Wang W (2002) An improved in situ and satellite SST analysis for climate. J Clim 15: 1609-1625. https://doi.org/10.1175/1520-0442(2002)015<1609: AIISAS $>2.0 . \mathrm{CO} ; 2$

Sellers PJ et al (1997) Modeling the exchanges of energy, water, and carbon between continents and the atmosphere. Science 275:502

Steiner AL et al (2009) Land surface coupling in regional climate simulations of the West African monsoon. Clim Dyn 33:869-892. https:// doi.org/10.1007/s00382-009-0543-6

Stensrud DJ, Bao J-W, Warner TT (2000) Using initial condition and model physics perturbations in short-range ensemble simulations of mesoscale convective systems. Mon Wea Rev 128:2077-2107. https://doi.org/10.1175/1520-0493(2000) $128<2077$ :uicamp $>2.0$. co; 2

Wei J, Dirmeyer PA (2010) Toward understanding the large-scale landatmosphere coupling in the models: roles of different processes. Geophys Res Lett 37. doi: https://doi.org/10.1029/2010g1044769

Wei J, Dirmeyer PA, Guo ZC, Zhang L, Misra V (2010a) How much do different land models matter for climate simulation? Part I: climatology and variability. J Clim 23:3120-3134. https://doi.org/10. 1175/2010jcli3177.1

Wei J, Dirmeyer PA, Guo ZC (2010b) How much do different land models matter for climate simulation? Part II: a decomposed view of the land-atmosphere coupling strength. J Clim 23:3135-3145. https://doi.org/10.1175/2010jcli3178.1

Wei J, Su H, Yang Z-L (2016) Impact of moisture flux convergence and soil moisture on precipitation: a case study for the southern United States with implications for the globe. Clim Dyn 46. doi:https://doi. org/10.1007/s00382-015-2593-2

Xie PP, Yatagai A, Chen MY, Hayasaka T, Fukushima Y, Liu CM, Yang S (2007) A gauge-based analysis of daily precipitation over East Asia. J Hydrometeorol 8:607-626. https://doi.org/10.1175/JHM583.1

Xue Y, Sellers PJ, Kinter JL, Shukla J (1991) A simplified biosphere model for global climate studies. J Clim 4:345-364. https://doi. org/10.1175/1520-0442(1991)004<0345:Asbmfg>2.0.Co;2

Yamada TJ, Koster RD, Kanae S, Oki T (2007) Estimation of predictability with a newly derived index to quantify similarity among ensemble members. Mon Wea Rev 135:2674-2687. https://doi.org/10. 1175/Mwr3418.1

Zhu J, Huang B, Marx L, Kinter JL, Balmaseda MA, Zhang R-H, Hu Z-Z (2012) Ensemble ENSO hindcasts initialized from multiple ocean analyses. Geophys Res Lett 39. doi:https://doi.org/10.1029/ 2012GL051503

Zhu J, Huang B, Balmaseda MA, Kinter JL, Peng P, Hu Z-Z, Marx L (2013) Improved reliability of ENSO hindcasts with multi-ocean analyses ensemble initialization. Clim Dyn 41:2785-2795. https:// doi.org/10.1007/s00382-013-1965-8 